\title{
Real Time Inventory Tracking Model in the Distribution Supply Chain of Airtel Airtime
}

\author{
Mr. Eddie Musana, Mr. Walter Okello, Assoc. Prof. Annabella H. Basaza-Ejiri
}

\begin{abstract}
This research considers designing and developing a Real Time Inventory Tracking Model (R.T.I.T.M) in the Business Supply Chain (SC) for an Airtel Authorized Distribution Company (DC) called Private Marketing and Trading Services (PMTS) Limited. The real-time inventory tracking model discloses a system for capture and storage of Airtel products that are not limited to Airtel Airtime (AA). Like Electronic (E) Recharge and airtime scratch cards.

It focuses on addressing a scenario where there is need to bridge the gap between the Telecom Company (Head Office) and the Independent Distributor Companies (DCs) in supplying AA as the major commodity surrounded by measures that need to control its sales within the different geographical area referred to as market boundaries or routes. This requires a given DC to manage sales within the routes assigned them in order to control selling airtime in routes that belong to other DCs. The selling of airtime outside the market routes of a given DC is referred to as Dumping of Airtime which is not allowed and may call for disciplinary measures whereby if severe may attract discontinuation from being an Authorized DC Agent for the Telecom Company in this study.

Hence market control by the Telecom Company upon the Distributor Company (Agents), however this paper discusses in detail as to why there is need for DCs to implement a Model that provides Real Time Inventory Tracking to prevent delays encountered in Restocking of Airtime products.

Therefore this paper explains the real time gap that exists between the Distributor Company and the Telecom Company, even though there are real time capabilities in place between the Customer (Final Consumer / End User) of the Airtime product and the Telecom Company. As the later enables the telecom company in controlling the market routes with purpose of avoiding dumping of $\mathrm{AA}$.
\end{abstract}

Index Terms - Distributor, Dumping Airtel Airtime (AA), Real Time, Restocking, Supply Chain and Telecom Company.

\section{INTRODUCTION}

As the Distributor Company (DC) sell airtime in the market, Direct Sales Representatives (DSR) request for more airtime stock from the DC, of which the airtime stock balances could be insufficient hence this reduces profits in the process of waiting for the next replacement of old stock of either the form of E - Recharge or Scratch card airtime.

Therefore there was need to design a real time model that enables distributors to keep track of their AA inventory stock, to prevent stock outs by serving the growing market of

Mr. Eddie Musana, Department of Computer, Busitema University, Faculty of Science and Education, Tororo, Uganda

Mr. Walter Okello, Faculty of Computing and Informatics, Mbarara University of Science and Technology, Mbarara, Uganda,

Associate Professor Annabella Habinka Basaza-Ejiri, College of Computing and Engineering, King Ceasor University, Kampala, Uganda approximately 7.6 million airtel subscribers within a market share of $38.6 \%$ [1]. Annually most average business spends between 25 to 35 percent of their operational budget on inventory costs alone [2], which is a large chunk of the budget dedicated to inventory control; Truly, research has proved that businesses with poor inventory management strategies spend higher on inventory costs reducing profits and greater chances for bankruptcy in the near future unlike businesses that keep track of their inventories on real time basis [2].

The digital airtime purchase of Electronic (E) Recharge may continuously be determined by the earlier airtime scratch cards of different airtime values in Uganda Shillings (UGX). Like 500/ $=, 1000 /=, 2000 /=, 5000 /=, 10,000 /=$ and $20,000 /=$ respectively.

This is because customers tastes and preferences differ, competitive strategy is needed to meet the demand on airtime products [3], it was found out that the sales of different restocked airtime denominations tended to vary.

Frequent purchase of low airtime denominations reduces sales and profits due to delays in restocking. The term "real-time means that the simulation's clock runs at the same speed as a real clock, also real-time means without significant delay in relation to process control and enterprise systems. The need to favour electronic Airtime Selling Machine by the Uganda Communication Commission (UCC) during a parliamentary debate to lift a ban on airtime scratch cards [4]. However besides lifting a ban on airtime scratch cards, measures could be put in place to sensitize the masses on the dangers of using bare hands to scratch Airtel cards as the material used to cover airtime digits contains heavy metals. It has silver nitric oxides, cadmium and aluminum. Since the dangerous chemicals get disposed to the finger nails upon scratching the airtime cards. Material that cannot be easily penetrated by light through heavy metals like Lead $(\mathrm{Pb})$ in an attempt to protect airtime digits from being illegally accessed by malicious people, may cause renal tubular damage among adolescents [5]. In addition, inventing protective items to scratch airtime cards could be preferred despite of other causes of cancer illnesses as Telecom Companies in other parts of the country may continue to either use airtime scratch cards alongside Electronic (E) Recharge.

\section{PROBLEM}

Delays in restocking due to poor tracking of different airtime denomination sale values in reference to scratch cards has a direct relationship to poor clustering of sales in E-Recharge of airtime that have resulted into losses and an approximation of 
26.9 percent annual loss in failing to meet target sales [] In addition, many average businesses without proper inventory tracking incur up to $25 \%$ to $35 \%$ annually of their budget to cater for inventory uncertainties [2]. At the time of the study, the Airtel distributor stored records in sales day books, invoice books and receipt books where the information is later transferred into Microsoft Excel package software, creating a delay in decision making on how much and when to restock airtime that is to be sold by the Distributor to Retailers.

\section{OBJECTIVE OF THE STUDY}

To design a model for Real Time Inventory tracking in the distribution supply chain of $\boldsymbol{A A}$.

\section{SCOPE OF THE STUDY}

The physical scope was limited to the procedures involved by the Distributor Agent in obtaining both $\boldsymbol{A A}$ serial numbers and $\mathrm{E}$ - Recharge airtime from Airtel Telecom Company; and consumption by the final consumer. The areas where the Distributor trades in are called "market territories" these include the areas of Zana, Massajja, Salama, Kanaba / Kigo, End Corned, Najja, Luwafu, Makindye, Kobil and Namasuba with in Kampala Uganda.

Purposive sampling was used to choose areas along Entebbe Road having many airtel kiosks, due to increasing demand. Many venders sell airtime on the road during traffic jam and along the road. Uganda has the second largest youngest population in the world below 25 years according to World Bank reports [7] and take mobile technology as their technology of choice and own several phones with many network lines.

In the technical scope, a real time model required the use of internet facility and system automation capabilities embedded in programming techniques, MySQL database, programming interface and user interface for a web based application that ensured remote access of real time information resulting to improved decision making, minimum time is used in making decisions and analysis could easily be made. For the time scope, the research was undertaken within the period of one year in concluding the master's program of Masters of Science in Information Systems

\section{SIGNIFICANCE OF THE STUDY}

There is a faster and quicker mechanism to track airtime inventory records by the designed model, easy access of sales and returns by the Distributor from a remote location. The study solves the problem of businesses incurring expenses of between $25 \%$ to $35 \%$ of the budget in catering for inventory uncertainties due to lack of proper inventory management [2], reduced time to make decisions. Like What airtime values to restock? and when to restock airtime?

Business Process Management (BPM) is the organized flow of business activities. Many studies show that inventory management permeates decision-making in countless firms [] and seeks to answer key questions that are influenced by various circumstances such as when to order, how much to order and how much stock to be kept as safety stock by [9].
An integration methodology design of tools is enabled to improve visibility, communication reliability and automate $S C$ management results from field observations by [10].

\section{LITERATURE REVIEW}

There are ten times as many mobile phones as landlines in sub-Saharan Africa and 60 percent of the population has mobile phone coverage. The subscriptions to Mobile phones increased by 49 percent annually between 2002 and 2007, as compared with 17 percent per year in Europe by [11]. Airtel being the $2^{\text {nd }}$ largest telecoms operator in Uganda, Perhaps the major development would be the merger with Warid Telecom, which saw the network of subscribers grow to over 7.2 million under the Airtel brand [12].

According to [13], [14], Supply Chain $(\boldsymbol{S C})$ and Supply Chain Management (SCM) has been studied and play a significant role in corporate efficiency. $\boldsymbol{S C}$ integration has contributes to the important spurt in research, practice and theory of $\boldsymbol{S C}$ disclosed from literature review. According to [15] $\boldsymbol{S C M}$ refers to "a set of methods used to effectively coordinate suppliers, producers, depots, and stores, so that commodity is produced and distributed at the correct quantities, to the correct locations, and at the correct time, in order to reduce system costs while satisfying service level requirements. The fundamental notion of these definitions is that a $\boldsymbol{S C}$ must be controlled in order to be fast and trustworthy, cost-effective and flexible enough to meet customers' requirements.

The choice of the most adequate R.T.I.T.M essentially is an empirically-based decision; that requires use of simulation, scenario analysis and incremental cost analysis by [9] or quantitative conceptual schemes or classification approach by [16]. $\boldsymbol{S C}$ analytics refers to the usage of different application packages in the efficient functioning of the four basic processes of planning, sourcing, making and delivering the final product by [17].

Honorable Frank Tumwebaze the Minister for ICT and National Guidance addressed the dialogue with Members of Parliament (MPs) that Uganda Communication Commission $(\boldsymbol{U} \boldsymbol{C} \boldsymbol{C})$ held at Parliament on $9^{\text {th }}$ August, 2018. Concerning the ban on airtime scratch cards which was imposed by $\boldsymbol{U C C}$, the government communications regulator came into effect at the end of July 2018 in favour of electronic airtime loading system, The R.T.I.T.M study was carried out in 2017. However the Minister directed not to ban scratch cards abruptly to consider rural people, MPs unanimously agreed to maintain use of scratch cards and that its phase out be determined by the market forces of demand [4].

Lean and real-time data capturing tools is developed and implemented in Integration methodology of Virtual Design and Construction. Improves alignment between demand and supply, reduces distortion of demand information, savings time and efforts was achieved in a field trial for the $\boldsymbol{S C M}$ of Airtime scratch cards. Having serial numbers help improve productivity hence translating the scope of work on the R.T.I.T.M in the $S C$ in $\boldsymbol{D C s}$ [10].

\section{CAUSES OF INVENTORY DELAY}

Since the R.T.I.T.M was to minimize delays in restocking 
of $\boldsymbol{A A}$ at the $\boldsymbol{D C}$, two categorized causes of restocking delays comprise of operational and behavioral causes. The operational causes result from errors in demand forecasting, order batching, gaming due to perceived or real shortage and discount fluctuations, the cause of restocking delay is documented practically and the techniques to eliminate the delay are an important part of the tool kit in $\boldsymbol{S C}$ design [18].

The behavioral causes of delays included experimental studies explanation emphasizes the bounded rationality / reasonableness of decision makers failing to adequately account for feedback effects and time, people do not adequately account for the time delays, nonlinearities and feedbacks in the system [18].

\section{LITERATURE ON DESIGN OF R.T IN B.S.C AND IMPLEMENTATION}

The research study aimed at investigating how to control and integrate $\boldsymbol{S C}$ based on demand - driven principles and sharing $\boldsymbol{R} \boldsymbol{T}$ information and proposed unified $\boldsymbol{S C}$ model based on theory, this research is supported by a set of principles clarified in this case example of a Telecom $\boldsymbol{D C}$ similar to [19].

Its known that Tan's framework of $\boldsymbol{S C M}[\underline{20}]$ enables the design and development of the R.T.I.T.M in the Telecom distribution $\boldsymbol{S C}$ of $\boldsymbol{A A}$. Since the framework highlights the application of pull based control principles, advanced visualization, automation of decision support.

Illustration of design for RT in airtel Distribution SC.

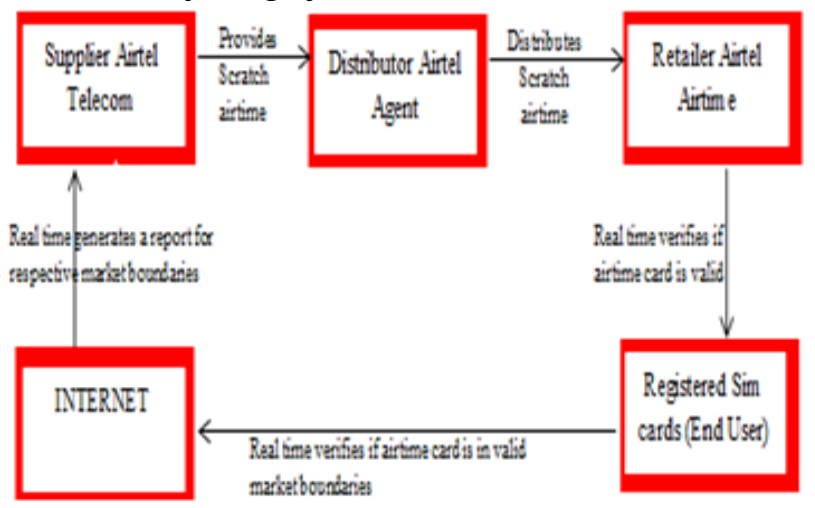

Fig 1: Manifests a real time gap between distributor and Telecom Company.

The model above shows how the Telecom Company monitors operations of $\boldsymbol{D C s}$ in the market boundaries by checking where the airtime was loaded and matching the nearest Masts "Boosters", serial number of $\boldsymbol{A A}$ is verified with that issued to DC to find out whether airtime was loaded from a correct market boundary of a given distributor. It confines to enforcing discipline among the Airtel $\boldsymbol{D C s}$ to avoid dumping airtime outside their market areas. However we aim at enabling the distributor to automatically track the inventory levels before Airtel Uganda (AU) informs DCs that they are running out of airtime. The Telecom Company informs $\boldsymbol{D C} \boldsymbol{s}$ only after subsequent loading of airtime by the final customer and it finds that the distributor needs to straight away restock more airtime after Retailing. This is intended to minimize and avoid a situation when consumer demand for airtime is higher than the sales referred to as Bullwhip Effect [21].
Small and medium sized enterprises in emerging countries are challenged in gaining competitive advantage. However the success and survival of business in dynamic and fast changing markets heavily depends on being part of an effectively managed $\boldsymbol{S C}$ [22] and also adopting innovative means of doing business in $\mathbf{S C}$ domain [23]. In reality, Small Medium Enterprises (SMEs) are comprised and embedded in the large $\boldsymbol{S C s}$ and sustained performance is ensured [24]. In addition, both Information Systems (IS) and related technologies enable the building of unified supply networks that link suppliers to customers thus integrate business processes for quick and effective information management. It implies that the long-term success and survival of $\boldsymbol{S M E S}$ is supported by $\boldsymbol{S C M}$ and $\boldsymbol{I S}$.

\section{SUMMARY ON INVENTORY MODELS}

The study summary includes Inventory models, Assumption and Examples. Economic Order Quantity determines optimal inventory policy for goods produced by firms and analyses stock keeping units where demand is known at a constant rate, its demerit is long shelf life however items are monitored by a continuous review system, examples include Allen Appliance Company (AAC) and wholesale of toasters, mixers [25]. Production Lot Size Model Determines items' optimal policy if demand rate is constant, production is in excess capacity, Production line does not produce same products, Items are produced in butches and resumes when inventory is nearly depleted, examples include Pharmaceutical company, soft drink bottlers, cosmetics companies, ice cream making, furniture making [25]

Planned Shortage Model backordering phenomenon is used to wait for delivery of merchandise, high holding cost due to low demand no customer is lost due to stock out since back ordering is used, time dependency and time independency are incorporated in this this model however the demerit is delays are involved, examples include purchase of new car, furniture or specialty parts with detailed specifications.

Single-period Inventory Model. It identifies the amount of inventory to purchase given a perishable product or single opportunity. Stocking is continuous by identifying optimal stocking, both stocking and service levels are discrete. The demerits are excess inventory left at the end of the period, unrealized profits leads to shortage costs, excess costs due to excess purchases and salvage value left at the end by the year [26], examples include Holiday decorations, Christmas trees, long stemmed red roses, newspapers and magazines.

Multi Echelon (level) model has layers of suppliers across multiple distribution centers and products are outsourced. Assumptions include Central or Regional Distribution Centers (RDC) is the first place for shipment to forward Distribution Centers (DCs) faced by customers. The demerits include complex interdependency between stages, chronic excess inventory, long lead time, demand uncertainty and supply volatility; the merits include safety stock buffers, an example is Nike's distribution network that has 7 RDCs and more than 300,000 DCs serve end customers [27].

Real time Inventory Model enables remote access, 
unlimited database storage, stock levels, $\boldsymbol{A} \boldsymbol{A}$ values, total stock, total sales, available stock, the percentage stock level, Assumes no time delays are allowed advantages are reduced production time (Toyota), negotiation with supplier to carry inventory on behalf of supplier (Dell Computers), distributors and retailers only order after the customer has placed an order. Examples include building real time inventory for Construction materials, Toyota, Dell Computer manufacturing, Drop-shippers, McDonald's fast food restaurant assembly of product is made only when an order is made [28]

\section{METHODOLOGY, MATERIALS AND METHODS}

The study design was identified; a target population was basically used and followed ethical procedures to collect data; through personal participation, observation, discussing with the company and academic participants, documented project reports, looked at other researched projects and relevant literature. Tested and analyzed Model results and findings.

The knowledge support in action research is adopted as a method for information systems research [29] as well as developing models for R.T.I.T.M in the distribution $\boldsymbol{S C}$. Action research is viewed as a cyclical process with five phases: diagnosing, action planning, action taking, evaluating, and specifying learning. The infrastructure within the client system and the action researcher maintain and regulate some or all of these five phases jointly as shown in figure below.

A. THE CYCLICAL PROCESS OF ACTION RESEARCH DESIGN

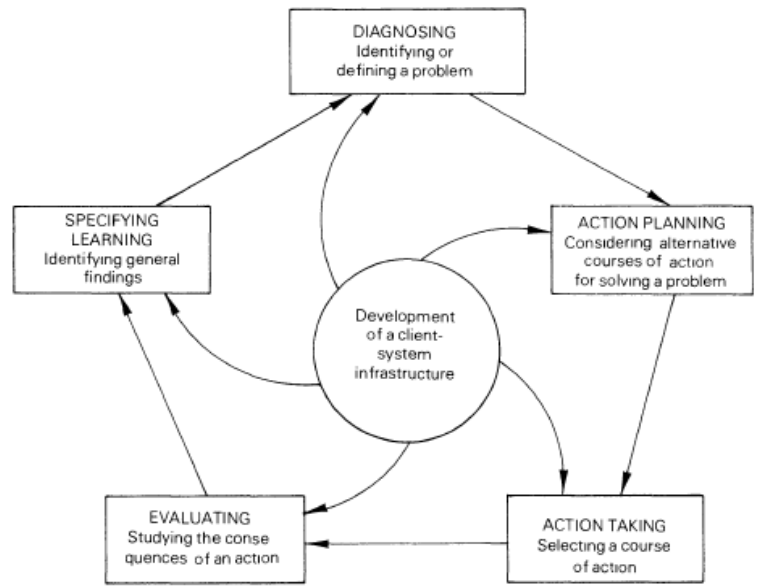

Fig 2: The cyclical process of action research [30]

B. SAMPLING TECHNIQUE

The Private Marketing and Trading Services (PMTS) Limited is headed by a person called DSRs headed by Area Sales Manager and some supervisors. PMTS Limited comprises of. PMTS Limited comprises of at least 33 employees of which 12 personals involved to keep records and storage of Airtel airtime stock, implying that by purposive sampling, $(12 / 33 * 100) \%=36 \%$ of the sample population was involved in the study.

C. SAMPLE SIZE

Solven's formula was used to compute the sample size using the formula:

$\mathrm{n}=\frac{\mathrm{N}}{1+\mathrm{N}(\mathrm{x})^{\mathrm{A}_{2}}}$

Where: $\mathrm{n}=$ sample size;
$\mathrm{N}=$ Target population; and ${ }^{\propto}=$ level of significance at $=$ 0.000

$$
\mathrm{n}=\frac{12}{1+12(0,000)^{n_{2}}}, \quad \mathrm{n}=\frac{12}{1+0}, \quad n=12
$$

All the 12 respondents were considered because of the small number; however we encourage future research to be carried out using a big population size, or even considering more $\boldsymbol{D C} \boldsymbol{s}$ in other future researches.

D. THE CURRENT STATE, LIMITATIONS, THE GAPS AND SOLUTION

The figure below summarized the current state of Authorized Distributor, limitations, bridging the gaps and solutions.

\begin{tabular}{|c|c|}
\hline $\begin{array}{c}\text { Authorized Distributor } \\
\text { Current State }\end{array}$ \\
\hline$\checkmark$ & Sales day books \\
$\checkmark$ & Receipt books \\
$\checkmark$ & Invoice books \\
$\checkmark$ & Microsoft Excel \\
\hline
\end{tabular}
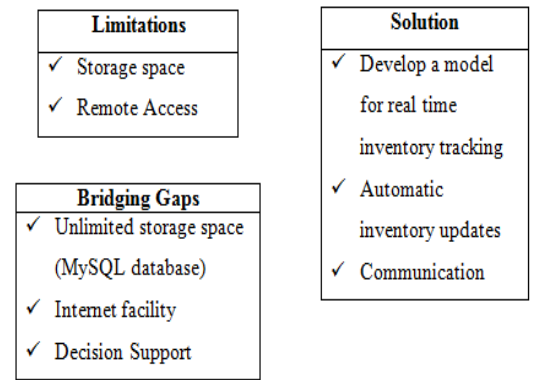

Fig 3: Supports to design and model R.T.I.T.M in the DSC E. THE REAL TIME GAP IDENTIFIED IN THE INVENTORY TRACKING MODEL

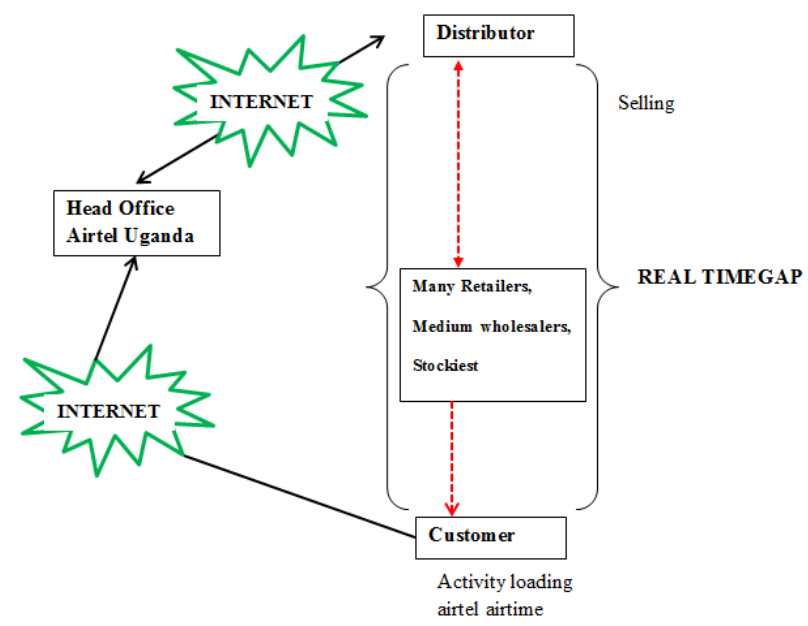

Fig 4: Real time gap identified in the R.T.I.T.M

$\boldsymbol{R} \boldsymbol{T}$ is enabled by Internet signified by the green cloudy shape and the red broken pointed arrow lines signify the $\boldsymbol{R} \boldsymbol{T}$ gap. 


\section{MODEL BUILDING SEQUENCE}

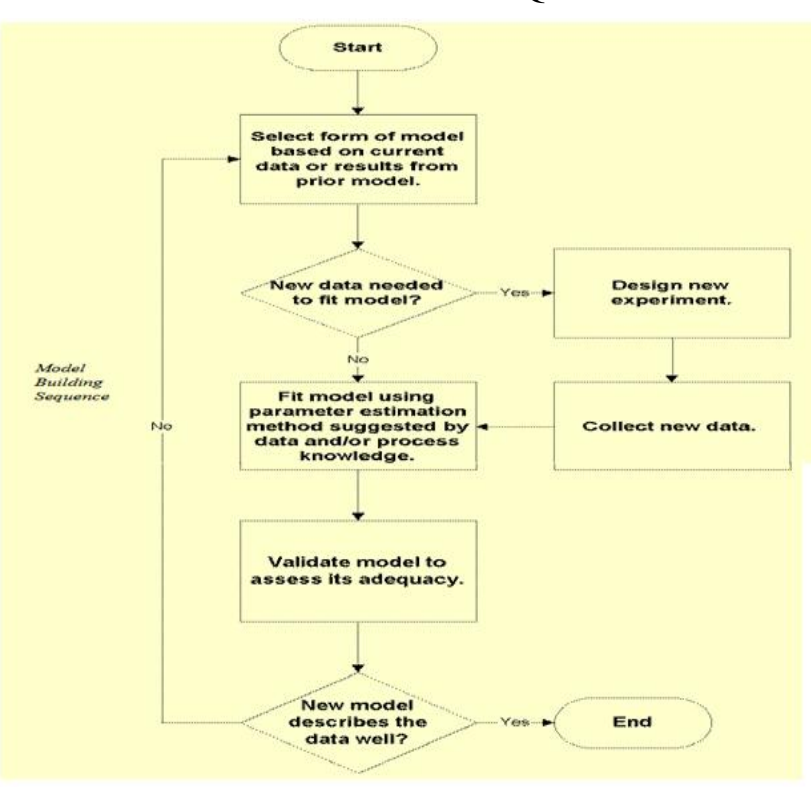

Fig 5: Model building sequence flow chart

At the $\boldsymbol{D C}$, records are stored and kept in hard copy by writing in physical books and printing; including Microsoft Excel and Microsoft word, emails. Internet was used daily to register sim cards, swapping, activating sim cards, sending and receiving mails and updating application software upgrades.

\section{A. MODEL DESIGN}

The R.T.I.T.M of airtel airtime was developed by reviewing literature above. Unifying Modeling Language $(\boldsymbol{U M L})$, the Entity Relationship Diagram (ERD) was used illustrate and show relationships among the various model components, the designed model.

The database was identified then the model runs to capture and initialize the default parameters. Therefore real time of the airtel airtime inventory is obtained to minimize Delay in restocking of airtime and check parameters. Automatically generated stock reports are used by the $\boldsymbol{D C s}$ on decision making about restocking the airtel airtime.

\section{B. UNIFIED MODELING LANGUAGE (UML)}

The use case comprised of scenarios describing an interaction between a user and the system. It shows the processes that acted on data as it moves through the different processes in the system.

In this report the following Unified Modeling Language (UML) symbols were used to represent the respective meanings.

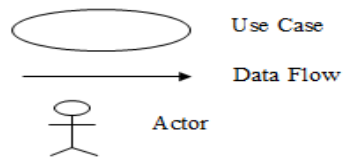

\section{LOGICAL FLOW OF THE MODEL}

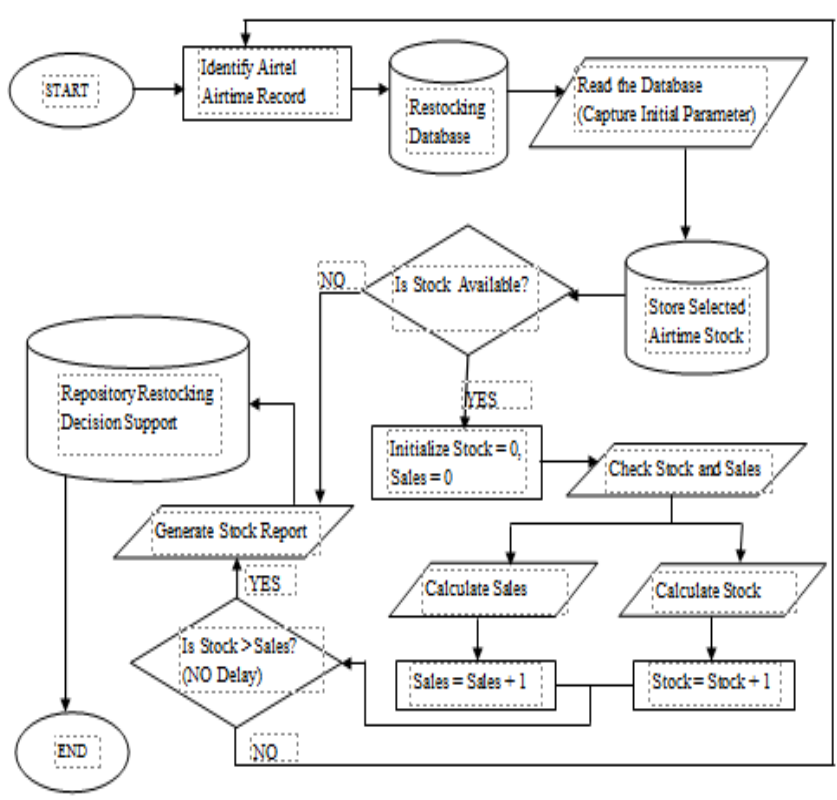

Fig 6: The R.T.I.T.M flow chart.

D. USE CASE DIAGRAM (UCD)

The Use Case diagram represented a wide setting of the system so as to deliver the basic requirements to the users as below.

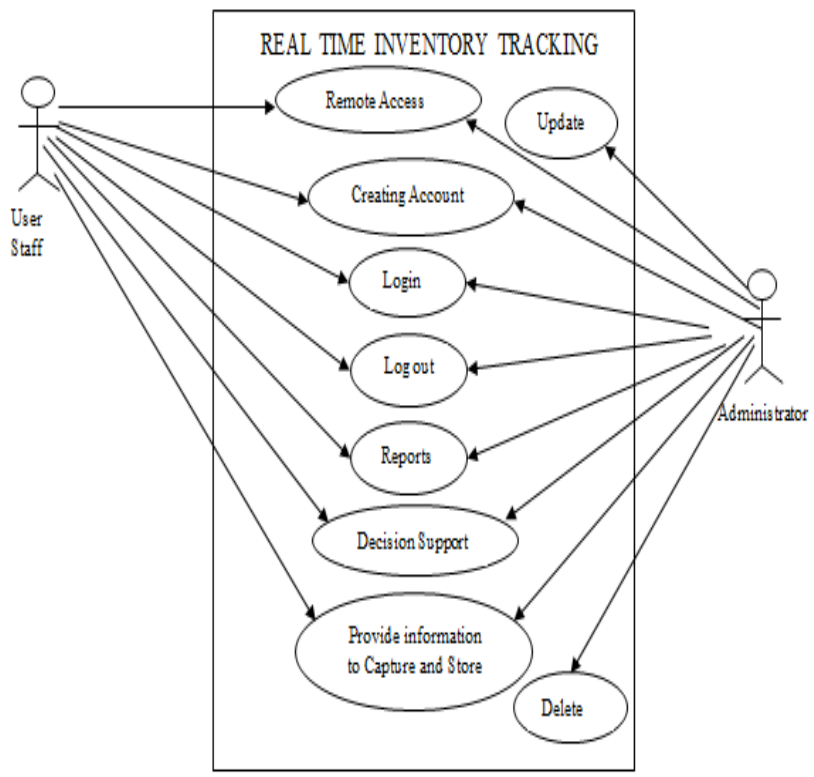

Fig 7: The Use Case Diagram

E. CONTEXT FLOW DIAGRAM (CFD) FOR AIRTEL $\mathrm{DC}$

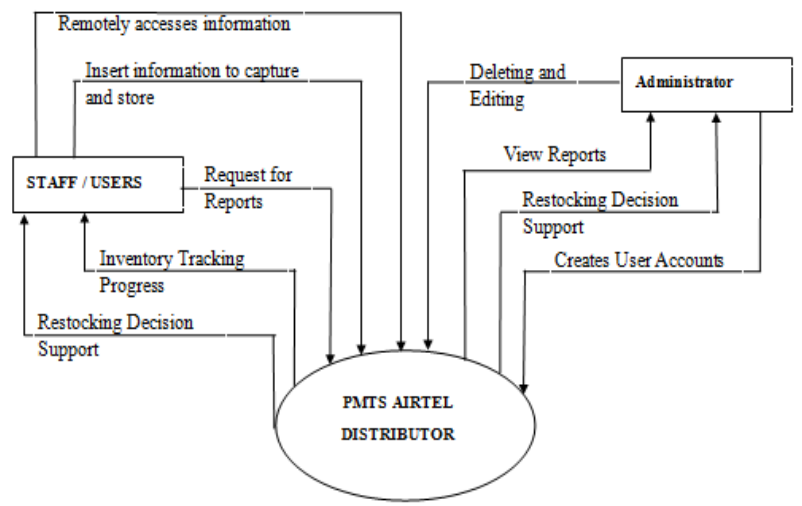

Fig 8: The CFD of real time inventory tracking.

This $\boldsymbol{C F D}$ shows the processes that take place at the $\boldsymbol{D C}$ 
(PMTS) Limited; the external entities included the Staff / User and Administrator. The data flows directs flow of information that required the administrator to create user accounts, capture / editing records, view / request reports and make restocking decision support and remotely access information.

\section{F. DATA FLOW DIAGRAM (DFD)}

DFDs are a tool to show an abstract and conceptual representation of data in a system. The diagrams below represent the flow of data in the Model.

$\underline{\underline{\mathrm{KEX}}}$
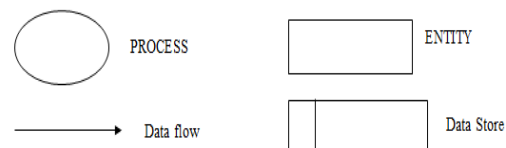

G. THE DFD OF THE R.T.I.T.M FOR AIRTEL DISTRIBUTOR COMPANY

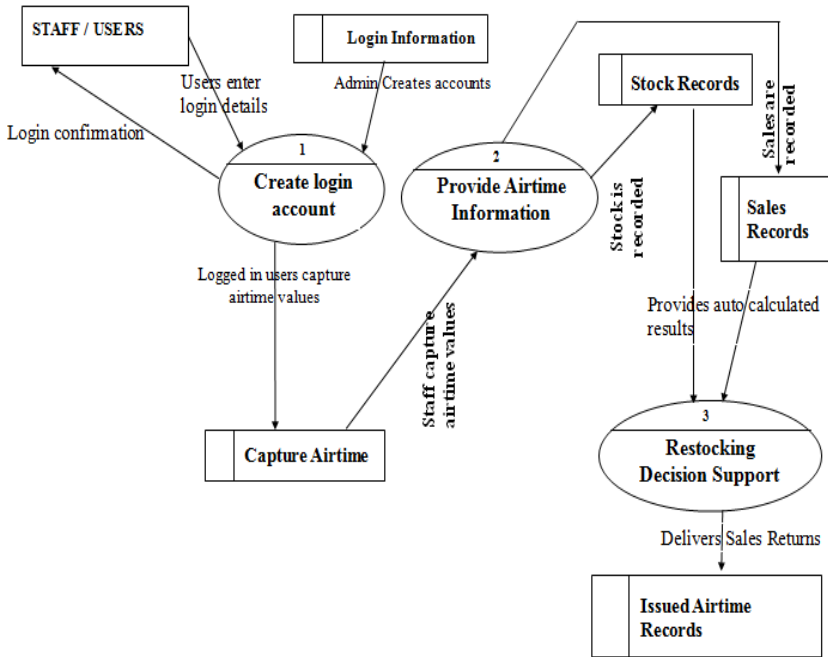

Fig 9: DFD for Real Time Inventory tracking. H. DATABASE STRUCTURE ARTIFACT (DSA)

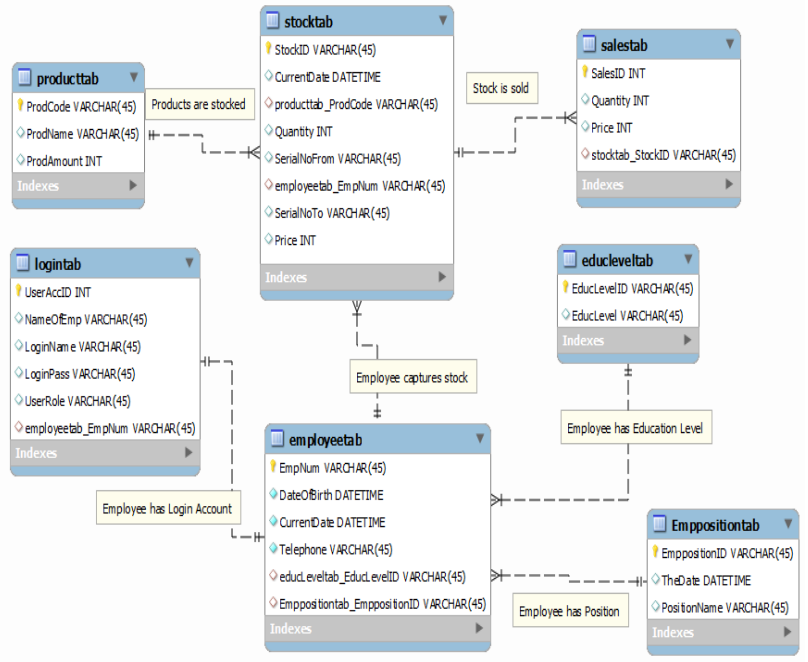

Fig 10: $E R D$ for the model.

The $\boldsymbol{E} \boldsymbol{R} \boldsymbol{D}$ had the following tables: - Login table: To capture information about the users of the R.T.I.T.M system. The Employee table: To capture employee information. Product table: Capture the product of airtel airtimes. Stock table: Captures details of airtel airtime stock. Sales table: Captures sales records and sales reduce the amount of available stock. Among other tables such as Education Level and Employee Position having attributes in the DSA in Fig 10

\section{R.T.I.T.M OF AIRTEL AIRTIME}

The diagram is the model designed to track airtel airtime inventories

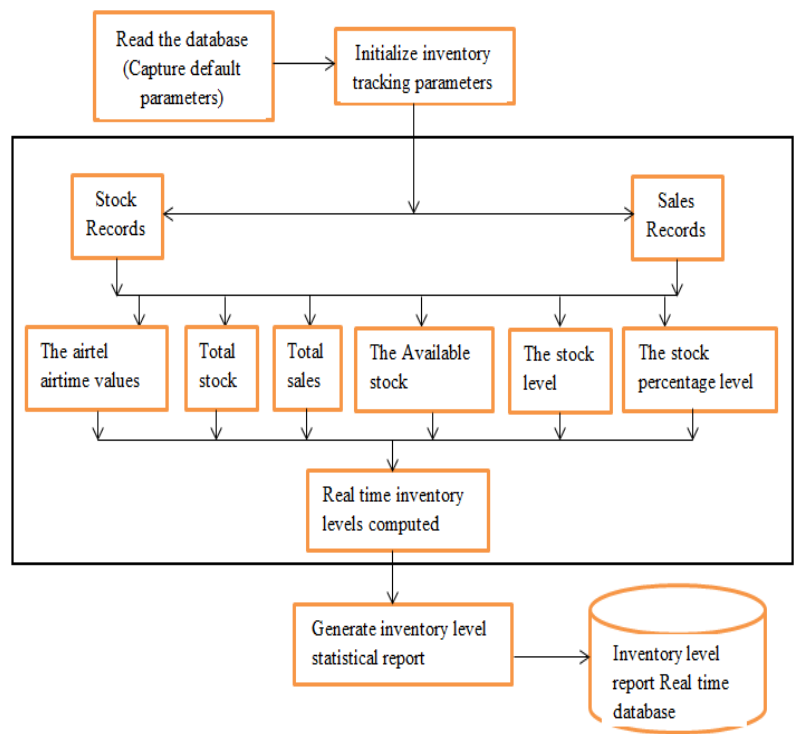

Fig 11: R.T.I.T.M of airtel airtime products.

\section{DISCUSSIONS AND RELEVANCE}

Real Time $(\boldsymbol{R} \boldsymbol{T})$ systems track up to date reliable information with support of both hardware and software technology to facilitate remote access information. Real-time system controlled environment receive and process data thus returning sufficient and quick results that time affect the environment by [31].

Requires one or more of synchronous programing languages, real-time operating systems and real-time networks that provided essential frameworks on which the real-time software applications was built.

The forces of demand and supply change over time due to difference in customer tastes and preferences, the retailers and stockiest tend to buy or order for $\boldsymbol{A A}$ that is mostly consumed by the end users. The imbalance in the levels of airtime stock at a given moment changes due to the increase in the forces of demand unforeseen by distributors clearly explained by the "bullwhip effect" due to data distortion in the $\boldsymbol{B S C}[21]$.

\section{FINDINGS}

There is inadequacy in accounting for the time delays, nonlinearities and feedbacks in absence of real time systems.

DCs tend to place orders depending on the gap between the inventory targets and the current inventory levels including on hand stock. As a result, insufficient weight is given to the supply line of unfilled orders or unreceived ordered stock.

The study improves $\boldsymbol{S C}$ speed and reliability, constrains in implementing $\boldsymbol{S C}$ amidist financial, trust and political issues reduces resource consuption.

The model improves the real time capabilities and inventory tracking to control and minimize the "bullwhip effect" it maintains steady stock turnover and minimizing losses when the customers demand excides the airtime sales by the $\boldsymbol{D C}$.

This contributes to literature in R.T.I.T.M of airtime in DCs of Telecom Companies of scratch airtime products and 
$\boldsymbol{E}$ - Recharge airtime in Uganda as a whole since most DCs share similar challenges in Uganda. It allows more studies on R.T.I.T.M research on major $\boldsymbol{D C \boldsymbol { s }}$ in developing countries.

Delays in restocking reduced the weekly sales targets and monthly sales targets.

\section{RESULTS}

The R.T.I.T.M in the $\boldsymbol{D S C}$ was designed and developed to minimize restocking delays. Timely decision making in restocking airtel airtime was enabled.

Other results arose from the scale that was designed to ascertain Stock levels as being Very High, High, Moderate, Low and Very Low.

The model was tested and validated using the scale below

\begin{tabular}{|l|l|}
\hline Stock Percentage & Interpretation \\
\hline & Stock Levels (Inventory tracking) \\
\hline$\leq 0$ & Critical Stock Level \\
\hline $0 \leq 29$ & Low Stock Levels \\
\hline $30 \leq 49$ & Average Stock Levels \\
\hline $50 \leq 69$ & High Stock Levels \\
\hline $70 \leq 100$ & Very High Stock Levels \\
\hline
\end{tabular}

Table 1: Interpretation of Stock Levels.

\section{TESTING OF ARTIFACT}

Statistics below are derived from the artifact of the Stock Levels of airtel airtime at the $\boldsymbol{D C}$ on real time remotely.

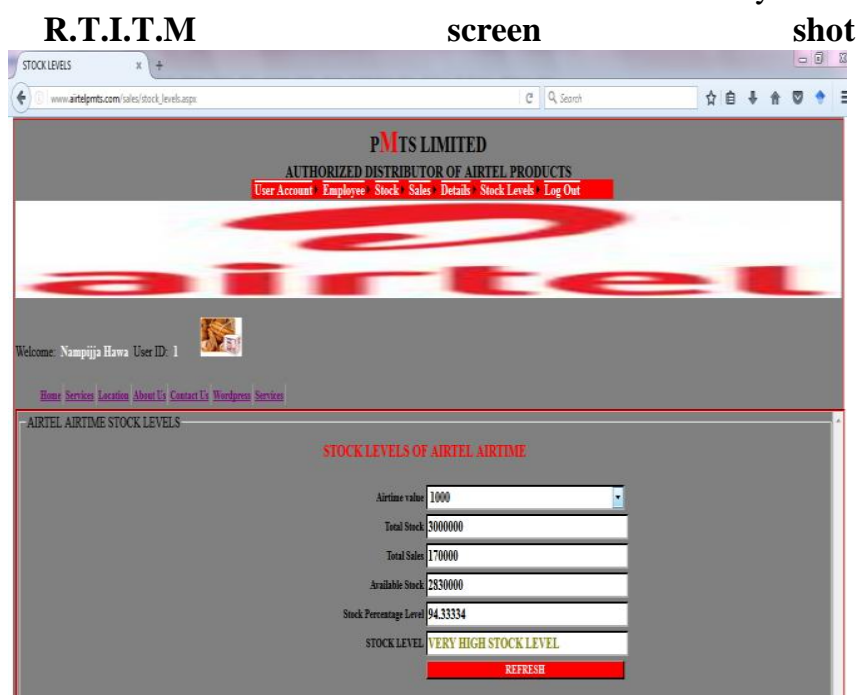

Fig 12: Very high stock levels for airtel airtime of value $1000 /=$

\section{LIMITATIONS OF THE STUDY}

Limitations in this empirical study include:-

1) The proposed model was only tested at PMTS Limited the DC of Airtel products. It is necessary to test the model in other major DCs because different cultures, beliefs and values affect implementation of R.T.I.T.M in the distribution $\mathbf{S C}$ of airtime.

2) The study was conducted within a limited geographical context.

3) The sample size was very small.

\section{RECOMMENDATIONS}

Employ business solution that uses real time analytics under one platform to make powerful sales and operations planning solutions that has a unified data model for different demand levels, finances and $\boldsymbol{S C}$ to provide instant responses.

Mobile devices allow quick access to accurate information and data for quick inventory decisions in the $\boldsymbol{D C}$, to eliminate errors and delays associated with a paper-based operation, improves accuracy, efficiency and speed of business [32].

\section{CONCLUSION}

The study focused on R.T.I.T.M to avoid time delays, ensured remote access of stock and it aimed at reducing overhead expenses while ensuring availability of stock, lowers business cost, promotes fastness efficient and competitiveness in $\boldsymbol{S C}$ handling, minimized storage of excess inventory thus lowering warehouse costs, better customers service / satisfaction through R.T.I.T.M.

Different inventory models are summarized based on assumptions, merits, demerits and examples in pages $3-4$. It emphasizes R.T.I.T.M in the study.

\section{ACKNOWLEDGMENT}

The success in this journal paper has been made possible due to the support of my family that is my ultimate role models. I am greatly indebted to Mr. Walter Okello and Associate Professor Annabella Habinka Basaza-Ejiri my coauthors for supporting me and to the staff of Airtel Authorized Distributor Company called PMTS Limited with whom I had a pleasure to work during the research. We thank Almighty God for the generous blessings towards the successful completion of this paper.

\section{REFERENCES}

[1] Cartesian. (2015). Mobile Network Access for Mobile Virtual Network Operators MVNOs. Available: http://www.ucc.co.ug/files/downloads/SMP Report_Mobile\%20Netw ork\%20Access_April\%202015.pdf

[2] Scanco. (2014, 03/07/2020). The True Cost of Poor Inventory Management. Available: https://www.scanco.com/the-true-cost-of-poor-inventory-management

[3] Michieka H. I. (2008) Application of competitive strategies to the challenges of increased competition faced by Safaricom mobile phone airtime dealers in Nairobi Central Business District, University of Nairobi, 2008.

[4] Walube A. (2018, 3 July, 2020). Government Lifts ban on airtime scratch cards (Department of Official Report of the Hansard ed.) Available:https://www.parliament.go.ug/news/2137/govt-lifts-ban-airt ime-scratch-cards

[5] Sönmez F, Dönmez O, Keskınoğlu A. Kabasakal C. and Mır S. (2002) Lead exposure and urinary $\mathrm{N}$-acetyl $\beta \mathrm{D}$ glucosaminidase activity in adolescent workers in auto repair workshops, Journal of adolescent health, vol. 30, pp. 213-216, 2002.

[6] Semakula O. M. K. M.. (2015, 03rd July, 2020). Uganda: Five Year Later, Airtel Africa Still Struggling to Hit Targets. Available: http://allafrica.com/stories/201509220958.html

[7] Busho.A. (2014, 3/07/2020). Mobile Market Look: Uganda. Available: https://mobilemediainfotech.wordpress.com/tag/airtel/

[8] Dumas M, La Rosa M, Mendling J, and Reijers H. A, (2013) Fundamentals of business process management vol. 1: Springer, 2013.

[9] Wanke P. (2012) A conceptual framework for inventory management: focusing on low consumption items, Gestão \& Produção, vol. 19, pp. 677-687, 2012

[10] Bouzayani W. and Dhiaf M. M. (2013) Real time supply chain management: Co-modeling of totally supply chain solution, in Advanced Logistics and Transport (ICALT), 2013 International Conference on, 2013, pp. 545-549.

[11] Aker J. C. and Mbiti I.M, (2010) Mobile phones and economic development in Africa, The Journal of Economic Perspectives, vol. 24 pp. 207-232, 2010 . 
[12] Rahman A, (2013) Analyze the present distribution mapping system and efficiency of Airtel Bangladesh Limited, 2013.

[13] Folorunso O, Ogunde A. O, Vincent R. O, and Salako O, (2010) Data mining for business intelligence in distribution chain analytics, International Journal of the Computer, the Internet and Management, vol. 18, pp. 15-26, 2010.

[14] Janvier-James A. M, (2012) A new introduction to supply chains and supply chain management: Definitions and theories perspective, International Business Research, vol. 5, p. 194, 2012.

[15] Vallespir B. and Alix, (2009) Advances in Production Management Systems: New Challenges, New Approaches: International IFIP WG 5.7 Conference, APMS 2009, Bordeaux, France, September 21-23, 2009, Revised Selected Papers vol. 338: Springer, 2010.

[16] Gandhi A. (2016) Literature review on impact of CRM, SRM, information sharing and goal congruence on retail-SCM, Indian Journal of Science and Technology, vol. 9, 2016.

[17] [Mandal, S. (2016) Towards a Relational Framework for Supply Chain Analytics, International Journal of Applied Engineering Research, vol. 11, pp. 4838-4843, 2016.

[18] Croson R, Donohue K, Katok E, and Sterman J, (2014) Order stability in supply chains: coordination risk and the role of coordination stock, Production and Operations Management, vol. 23, pp. 176-196, 2014.

[19] Dreyer H. C, Strandhagen J. O, Romsdal A, and Hoff A, (2009) Principles for Real-time, Integrated Supply Chain Control: an Example from Distribution of Pharmaceuticals, IFIP International Conference on Advances in Production Management Systems, 2009, pp. 187-194.

[20] Tan K. C, (2001) A framework of supply chain management literature, European Journal of Purchasing \& Supply Management, vol. 7, pp. 39-48, 2001.

[21] Lee H. L, Padmanabhan V, and Whang S, (2004) Information distortion in a supply chain: the bullwhip effect, Management science, vol. 50, pp. 1875-1886, 2004.

[22] Bayraktar E, Jothishankar M, Tatoglu E, and Wu T, (2007). Evolution of operations management: past, present and future, Management Research News, vol. 30, pp. 843-871, 2007.

[23] Wunder M, Hiete M, Stengel J, Schultmann F, and Simmleit N, (2012) Potential supply chain cost savings from innovative cold bitumen handling, International Journal of Logistics Research and Applications, vol. 15, pp. 337-350, 2012.

[24] Koh S.L, Demirbag M, Bayraktar E, Tatoglu E, and Zaim S, (2007) The impact of supply chain management practices on performance of SMEs, Industrial Management \& Data Systems, vol. 107, pp. 103-124, 2007.

[25] Wiley (2001). Inventory Models. Available: http://higheredbcs.wiley.com/legacy/college/lawrence/0471391905/err ata/ch08.pdf

[26] Stevenson W. J, and Hojati M, (2007) Operations management vol. 8: McGraw-Hill/Irwin Boston, 2007.

[27] Sanyal S, (2014, 5/07/2020). Multi-Echelon Inventory Optimization. Available:

http://cmuscm.blogspot.ug/2014/01/multi-echelon-inventory-optimizat ion.html

[28] Kiger D, (2016, 30/06/2020). Analyzing top examples of just in time inventory and production management. Available: https://davidkigerinfo.wordpress.com/2016/02/22/analyzing-top-exam ples-of-just-in-time-inventory-and-production-management

[29] Baskerville R. L, and Wood-Harper A. T, (2016) A critical perspective on action research as a method for information systems research, in Enacting Research Methods in Information Systems: Volume 2, ed: Springer, 2016, pp. 169-190.

[30] Susman G. I. and Evered R. D, (1987) An assessment of the scientific merits of action research, Administrative science quarterly, pp. 582-603, 1978.

[31] Martin J, (1965) Programming real-time computer systems, 1965.

[32] Napolitano M. (2013, 02/07/2020). Top 8 guidlines to improve inventory management. Available: https://www.mmh.com/article/top_8_guidelines_to_improve_inventor y_management 